\title{
Injuries and disorders among young ice skaters: relationship with generalized joint laxity and tightness
}

This article was published in the following Dove Press journal:

Open Access Journal of Sports Medicine

18 August 2014

Number of times this article has been viewed

\author{
Shinobu Okamura' \\ Naoki Wada' \\ Masayuki Tazawa' \\ Makoto Sohmiya' \\ Yoko Ibe' \\ Toru Shimizu' \\ Shigeru Usuda ${ }^{2}$ \\ Kenji Shirakura' \\ 'Department of Rehabilitation \\ Medicine, Gunma University \\ Graduate School of Medicine, \\ Maebashi, Gunma, Japan; \\ ${ }^{2}$ Department of Physical Therapy, \\ Gunma University School of Health \\ Science, Maebashi, Gunma, Japan
}

Correspondence: Shinobu Okamura

Department of Rehabilitation Medicine, Gunma University Graduate

School of Medicine, 3-39-22, Showa,

Maebashi, Gunma, Japan, 37I-85II

Tel +8I 272208655

Fax+8I 272208655

Email ksokamura@gmail.com
Abstract: This study retrospectively investigated 192 teenage speed and figure skaters with prior injuries documented by an athletes' questionnaire, who underwent a physical examination to assess their muscle tightness and generalized joint laxity. In all athletes, the degree of muscle tightness and joint laxity were measured by a standardized physical examination. A descriptive report of the types of injuries showed a predominance of fractures, ligament injuries, enthesitis, and lower back pain. Approximately $5 \%$ of all skaters tested positive for tightness, while $25.8 \%$ of figure skaters and $15.2 \%$ of speed skaters had generalized ligamentous laxity. Statistical testing showed an association between ankle sprains and muscle tightness, and an association between knee enthesitis and muscle tightness in skating athletes. There was also an association between lower back pain and generalized joint laxity, which held true only for the male skaters.

Keywords: sports injury, skating, junior athlete, tightness, joint laxity, medical checkup

\section{Introduction}

In recent years, skating at ice rinks has become widespread among average citizens. Previous reports have demonstrated that many injuries sustained while skating involve fractures of the upper limbs in average citizens engaging in the sport at the recreational level, particularly among obese or female individuals 50 years of age and older. ${ }^{1-3}$

At the sports level of skating, the activities comprise figure skating and speed skating, including short track skating, the features of which differ significantly. In the field of figure skating, $50 \%$ of injuries are traumatic, while $50 \%$ are due to overuse. Such overuse injuries are more common in single skaters, whereas acute injuries occur more frequently among pair skaters and ice dancers. ${ }^{4}$

The ankle is a common site of injury in figure skaters. ${ }^{46}$ In short track speed skaters, the two most common injuries occurring on the ice are lacerations from the knee down and ankle fractures. ${ }^{7}$ There is also a high incidence of lower back pain among both figure and speed skaters. ${ }^{4,5,7-9}$

However, little is known about skating injuries in young school athletes. Hence, in this study, the incidence of injuries and disorders were investigated among young school athletes, and the relationships between those and generalized joint laxity and/or muscle tightness were assessed.

\section{Materials and methods} Subjects

The participants received medical checkups with Gunma Prefecture's Amateur Sports Association for competitive athletes at the national athletic meet level. The medical 
checkups were performed by authorized sports doctors at Japan Sports Association and official association staff, who were coached regarding the medical checkups by the sports doctors. The checkups were conducted between April 2000 and March 2011. A total of 213 athletic skaters enrolled in the medical checkups and the data was acquired retrospectively from the charts.

Twenty-one athletes with an age of under 12 years and over 18 years were excluded. The remaining 192 athlete skaters were the subjects of the study, including 92 males and 100 females, with a mean age of $15.4 \pm 1.8(12-18)$ years. There were 33 figure skaters and 159 speed skaters; the mean age of the figure skaters was $14.6 \pm 1.8(12-18)$ years, and that of the speed skaters $15.5 \pm 1.7(12-18)$ years.

The subjects were asked to respond to a self-reported retrospective questionnaire about the athletic event(s) they participated in, their complaints, and their treatment history from the beginning of their skating to the present time, as well as the age at which the participant began skating. In all athletes the degree of joint laxity and muscle tightness were measured. The examiners who scored tightness and laxity were blinded to the subject's injury histories.

Ethical approval was obtained from the epidemiological ethics committee of Gunma University School of Medicine.

\section{Definitions of injuries and disorders}

In this study, we evaluated the injuries and disorders for which the athletes had needed medical treatments. Patients with injuries confirmed not to be due to skating were excluded from the analysis. Among patients with multiple sites of injury, the most recent injury was evaluated in this study. We classified these injuries according to the following definitions: fracture, muscular injury (which included partial muscle rupture of the thigh and lower thigh), ligament injury, meniscus injury of the knee, enthesitis (which included patellar or quadriceps tendinitis), tenosynovitis, periostitis, bursitis, lower back pain, lumbar disc herniation, and spondylolysis.

\section{Assessments of muscle tightness}

Three muscle tightness tests were performed: the finger to the floor test, the straight leg raise test (SLR), and Ely's test. The finger-to-floor distance (FFD) was measured and an FFD of $>0 \mathrm{~cm}$ was considered to be a positive result in this test. ${ }^{10,11}$

The SLR was carried out with the athlete lying supine with the lower limbs extended and feet relaxed. The examiner then raised each of the subject's lower extremities slowly to the point at which they felt resistance in the hamstring muscle. The range of hip flexion was assessed using a goniometer. An angle under $70^{\circ}$ was defined as indicating positivity for SLR tightness. ${ }^{12,13}$

The Ely test was performed to measure the degree of flexibility of the quadriceps muscle. The quadriceps-inhibited knee flexion angle was determined in order to quantify the rectus femoris tightness, with the patient prone and the hip extended, the heel-to-buttock distance (HBD) was measured. ${ }^{14}$ A HBD over $0 \mathrm{~cm}$ was defined as indicating rectus femoris tightness. In each athlete, at least one positive test was defined as indicating positivity for muscle tightness.

\section{Assessments of joint laxity}

The degree of joint laxity was assessed at five joints according to a previous study. ${ }^{15-19}$ The five elements of the scale were scored as "yes" or "no," as follows: 1) passive opposition of the thumb to the flexor aspect of the forearm; 2) passive hyperextension of the metacarpal phalangeal joint beyond $90^{\circ} ; 3$ ) hyperextension of the elbows by $10^{\circ}$ or more; 4) hyperextension of the knees by $10^{\circ}$ or more; and 5) ankle dorsiflexion over $45^{\circ}$. The simultaneous presence of joint laxity in three or more joints bilaterally was defined as generalized joint laxity.

\section{Statistical analysis}

The Mann-Whitney $U$-test was used to assess differences in the type of skating and gender. Pearson's chi-squared test was used to assess the differences in each parameter. The IBM SPSS Statistics 21 software program (IBM Corporation, Armonk, NY, USA) was used for the statistical analysis. A $P$-value $<0.05$ was considered to be statistically significant.

\section{Results}

The demographic data are shown in Table 1. All figure skaters were individual competitors. The "Others" in the speed skater group included skaters who had responded non-specifically or who had selected more than two items.

The rates of each type of injury and disorder sustained while skating are shown in Figure 1. In this study, fractures, ligament injuries, enthesitis, and lower back pain were all common. The region of the ligament injuries was the knee joints in three cases and ankle joints in 15 cases. The sites of enthesitis were one thigh and ten knee joints. The periostitis was localized in the lower thigh area in six out of eight skaters, and the others were affected at the thigh and foot.

The history of skating among the athletes with any type of fracture (5.0 \pm 1.4 years) was longer than that observed in the remaining athletes $(4.3 \pm 1.6$ years $)(P<0.05)$. No other 
Table I The demographic data

\begin{tabular}{|c|c|c|c|c|c|c|}
\hline & \multirow[t]{2}{*}{$\begin{array}{l}\text { Total } \\
(n=192)\end{array}$} & \multirow[t]{2}{*}{$\begin{array}{l}\text { Figure skater } \\
(n=33)\end{array}$} & \multicolumn{4}{|l|}{$\begin{array}{l}\text { Speed skater } \\
(n=159)\end{array}$} \\
\hline & & & $\begin{array}{l}\text { Short track } \\
\text { sprinter }(n=27)\end{array}$ & $\begin{array}{l}\text { Long track } \\
\text { sprinter }(n=5 I)\end{array}$ & $\begin{array}{l}\text { Long track distance } \\
\text { skater }(n=61)\end{array}$ & $\begin{array}{l}\text { Others } \\
(n=20)\end{array}$ \\
\hline Age (years) & $15.4 \pm 1.8(12-18)$ & $14.6 \pm 1.8(12-18)$ & $15.4 \pm 1.8(12-18)$ & $15.7 \pm 1.7(12-18)$ & $16.0 \pm 1.4(12-18)$ & $13.8 \pm 1.6(12-17)$ \\
\hline Female (\%) & 52.1 & 87.9 & 51.9 & 47.1 & 39.3 & 47.4 \\
\hline $\begin{array}{l}\text { Skating history } \\
\text { (years) }\end{array}$ & $4.4 \pm 1.6(0-10)$ & $3.6 \pm 1.5(0-6)$ & $4.6 \pm 1.8(2-9)$ & $4.4 \pm 1.5(I-9)$ & $4.8 \pm 1.6(1-10)$ & $3.8 \pm 1.2(1-6)$ \\
\hline
\end{tabular}

relationships were observed between the skating history and the occurrence of injury in this study.

There were statistically significant differences in the right SLR angle between the figure skaters and speed skaters $(P=0.014)$. On the other hand, the percentage of subjects with an FFD under $0 \mathrm{~cm}$ was significantly higher in males than in females $(P=0.003)$. Both the right and left SLR angles were significantly higher in females $(P=0.001$ and $P=0.006$ ). There were no statistically significant differences in the incidence of tightness, as judged based on the detection of at least one positive tightness test, between the groups divided according to the type of skating or gender. There were no associations between the length of skating history and the presence of muscle tightness in this study.

The rate of generalized joint laxity was $25.8 \%$ in figure skaters and $15.2 \%$ in speed skaters. The frequency of joint laxity in the right or left knee was significantly different between the figure skaters and speed skaters. No other joints exhibited a statistically significant difference between the two skating groups.
The athletes with at least one positive result among the three tightness tests (FFD, SLR, and HBD) exhibited a significantly increased incidence of ankle ligament injury. HBD tightness was also found to be associated with ankle ligament injury (Table 2). In addition, the analysis for all athletes revealed that the risk factor for the knee enthesitis was the SLR tightness (Table 2).

There were no significant differences in the incidence of injury according to gender, with the exception of lower back pain, in this analysis. Among the male athletes, the rate of lower back pain was related to generalized joint laxity $(P<0.05)$ (Table 3).

\section{Discussion}

Several previous reports have found muscle tightness and joint laxity to be risk factors for various sports injuries and disorders. ${ }^{19-25}$ However, little has been clarified regarding the associations between muscle tightness and/or joint laxity and the incidence of injury among athletic skaters, especially those in junior or senior high school. Therefore, in the present

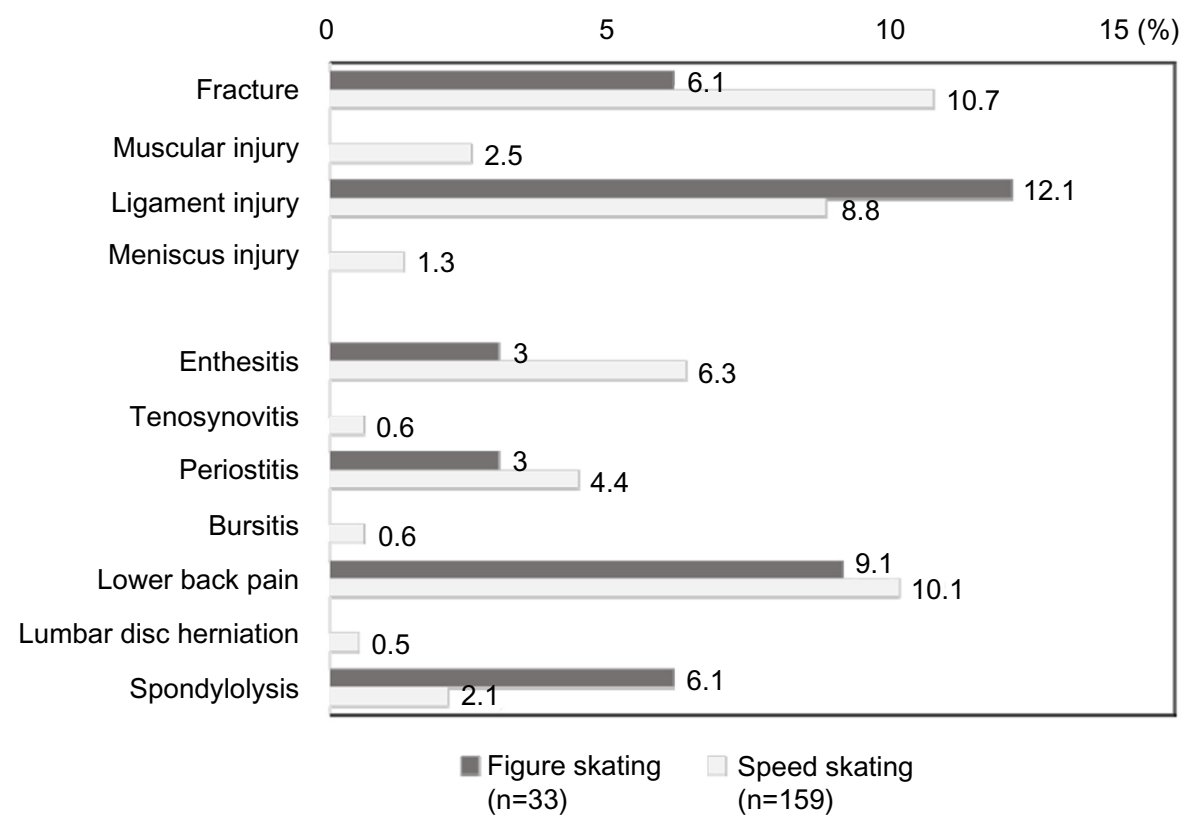

Figure I Percentage of the latest injury or disorder in skaters. 
Table 2 Risk factors for ankle ligament injury and knee enthesitis

\begin{tabular}{llll}
\hline & $\begin{array}{l}\text { Odds } \\
\text { ratio }\end{array}$ & $\mathbf{9 5 \%} \mathbf{C l}$ & P-value \\
\hline Ankle ligament injury & & & \\
$\quad$ FFD tightness & $\mathrm{I} .05 \mathrm{I}$ & $0.28 \mathrm{I}-3.933$ & $\mathrm{~ns}$ \\
HBD tightness & 3.9 & $1.275-11.926$ & $<0.05$ \\
Tightness positive & 6.878 & $1.508-31.372$ & $<0.005$ \\
Generalized joint laxity & 0.779 & $0.210-2.890$ & $\mathrm{~ns}$ \\
Right ankle joint laxity & 0.784 & $0.272-2.257$ & $\mathrm{~ns}$ \\
Left ankle joint laxity & 0.765 & $0.266-2.205$ & $\mathrm{~ns}$ \\
Knee enthesitis & & & \\
FFD tightness & 1.866 & $0.459-7.587$ & $\mathrm{~ns}$ \\
SLR tightness & 7.333 & $1.274-42.206$ & $0.0 \mathrm{I}$ \\
HBD tightness & $\mathrm{I} .8$ & $0.502-6.449$ & $\mathrm{~ns}$ \\
Tightness positive & 4 & $0.827-19.352$ & $\mathrm{~ns}$ \\
Generalized joint laxity & 0.784 & $0.161-3.830$ & $\mathrm{~ns}$ \\
Right knee joint laxity & $\mathrm{I} .05 \mathrm{I}$ & $0.287-3.855$ & $\mathrm{~ns}$ \\
Left knee joint laxity & $\mathrm{I} .028$ & $0.280-3.768$ & $\mathrm{~ns}$ \\
\hline
\end{tabular}

Abbreviations: $\mathrm{Cl}$, confidence interval; $\mathrm{FFD}$, finger-to-floor distance; $\mathrm{HBD}$, heelto-buttock distance; ns, not significant; SLR, straight leg raise.

study, the data obtained at medical checkups were assessed and the tendency toward injury and the relationship between such injuries and muscle tightness and/or joint laxity were analyzed.

Previous reports have demonstrated that ligamentous and/or meniscal injuries of the knee joint are uncommon in skaters. ${ }^{4,5,26,27}$ This study's data matched those of previous reports. The reasons underlying this phenomenon are believed to include the following: 1) in figure skating, the skater lands gliding backwards, requiring co-contraction of the quadriceps and hamstrings, which protects the ligaments and meniscus; ${ }^{26}$ and 2) there is a relative lack of fixation of the blade on the ice that occurs while skating. ${ }^{5}$

There was a difference in the right SLR angle observed between the figure and speed skaters in this study. One of the reasons for this difference is thought to be the fact that the speed skaters are only required to skate in a counterclockwise direction.

Our data indicated that muscle tightness is associated with ankle ligament injuries. Due to the support provided by their stiff boots, competitive skaters have relatively weak peroneal muscles, resulting in an increased incidence of ankle sprains. ${ }^{4,5}$ Although no previous reports have demonstrated

Table 3 Result of the chi-square analysis relating generalized joint laxity to risk of lower back pain

\begin{tabular}{llll}
\hline & Odds ratio & $95 \% \mathbf{C l}$ & P-value \\
\hline Generalized joint laxity & & \\
Male & 6.19 & $1.057-36.243$ & $<0.05$ \\
Female & 1.281 & $0.239-6.858$ & $\mathrm{~ns}$ \\
\hline
\end{tabular}

Abbreviations: $\mathrm{Cl}$, confidence interval; ns, not significant. a relationship between ankle injury and muscle tightness in skaters, our hypothesis is that muscle tightness in the thigh restricts the latitude of the lower legs, thereby increasing the susceptibility to ankle sprains.

In this study, there was an association between generalized joint laxity and lower back pain in male skating athletes. There was no report about the relationship between these two factors in skating athletes. However, a previous study demonstrated the risk factors associated with the development of lower back pain among ice skaters, which include a high, tight quadriceps femoris muscle, and tight hamstrings. ${ }^{21}$

Another reason why skaters experience lower back pain is thought to be the presence of secondary hip-spine syndrome, ${ }^{28}$ and the lumbar flexure caused by tightness of the iliopsoas muscle and the limitation of hip extension. Our hypothesis is that the limitation of hip extension while skating results in anterior inclination of the pelvis, which enhances lumbar flexure, thus causing lower back pain.

When evaluating the lower back pain in skating athletes, it is important to assess the viscoelasticity and strength of the hip flexor and extensor. Additionally, while speed skaters were skating, it was pointed out that the erector spinae group was overloaded because of the posture that was needed, and the lumbar disk was also overloaded because of the elevation of the upper extremities, thus leading to lower back pain. Therefore future studies should investigate the alignment through the lumbar spine to the hip joints at both resting and moving points.

This study is associated with some limitations. First, no detailed questionnaire was used regarding the subject's history of injury to identify the environment in which the injury occurred. Among skaters, off-ice training is one of the most common precipitating risk factors for injury, ${ }^{29}$ and we were unable to precisely evaluate the mechanisms underlying such injuries.

Secondly, the diagnosis of injury was made based solely on the results of the medical checkups conducted by sports doctors, which lacked diagnostic imaging examinations. The self-reporting and retrospective bias of injuries was also a limitation of this study.

Thirdly, the analysis employed a cross-sectional design, and the objectives were limited to junior athletes. During this period, there is a brittleness of the connection sites of tendons to bones because of the rapid growth in their height and the alignment of their frames. Because these factors are considered to be a trigger of skating disorders, both frequent medical check-ups and feedback on their information are necessary to help athletes reduce their risk of injury. 
Therefore, it is necessary to perform a longitudinal study in order to identify the precise risk factors for sports injuries among young school athletic skaters.

\section{Conclusion}

The incidence of injuries and disorders among young athletes engaged in figure and speed skating were herein summarized, and the associations between injury and muscle tightness and/or joint laxity were analyzed in this study.

The rates of lower back pain and lower extremity injury were high, and the presence of muscle tightness was found to be associated with enthesitis of the knee and with ankle ligament injuries among teenage athletic skaters. Among the male athletes, the rate of lower back pain was related to generalized joint laxity.

\section{Acknowledgment}

We wish to express our appreciation to the members of Gunma Prefecture's Amateur Sports Association for their technical support for the medical checkups.

\section{Disclosure}

The authors declare no conflicts of interest in association with this study.

\section{References}

1. van Lieshout AP, van Manen CJ, du Pré KJ, et al. Peak incidence of distal radius fractures due to ice skating on natural ice in The Netherlands. Strategies Trauma Limb Reconstr. 2010;5(2):65-69.

2. Barr LV, Imam S, Crawford JR, Owen PJ. Skating on thin ice: a study of the injuries sustained at a temporary ice skating rink. Int Orthop. 2010;34(5):743-746.

3. Radford PJ, Williamson DM, Lowdon IM. The risks of injury in public ice skating. Br J Sports Med. 1988;22(2):78-80.

4. Porter EB, Young CC, Niedfeldt MW, Gottschlich LM. Sport-specific injuries and medical problems of figure skaters. WMJ. 2007;106(6):330-334.

5. Smith AD. The young skater. Clin Sports Med. 2000;19(4):741-755.

6. Bradley MA. Prevention and treatment of foot and ankle injuries in figure skaters. Curr Sports Med Rep. 2006;5(5):258-261.

7. Dubravcic-Simunjak S, Kuipers H, Moran J, Simunjak B, Pecina M. Injuries in synchronized skating. Int J Sports Med. 2006;27(6): 493-499.

8. Quinn A, Lun V, McCall J, Overend T. Injuries in short track speed skating. Am J Sports Med. 2003;31(4):507-510.

9. Fortin JD, Roberts D. Competitive figure skating injuries. Pain Physician. 2003;6(3):313-318.

Open Access Journal of Sports Medicine

\section{Publish your work in this journal}

Open Access Journal of Sports Medicine is an international, peer-reviewed, open access journal publishing original research, reports, reviews and commentaries on all areas of sports medicine. The manuscript management system is completely online and includes a very quick and fair peer-review system.
10. Gauvin MG, Riddle DL, Rothstein JM. Reliability of clinical measurements of forward bending using the modified fingertip-to-floor method. Phys Ther. 1990;70(7):443-447.

11. Czaprowski D, Leszczewska J, Kolwicz A, et al. The comparison of the effects of three physiotherapy techniques on hamstring flexibility in children: a prospective, randomized, single-blind study. PLoS One. 2013;8(8):e72026.

12. Santonja Medina FM, Sainz De Baranda Andújar P, Rodríguez García PL, López Miñarro PA, Canteras Jordana M. Effects of frequency of static stretching on straight-leg raise in elementary school children. J Sports Med Phys Fitness. 2007;47(3):304-308.

13. de Lucena GL, dos Santos Gomes C, Guerra RO. Prevalence and associated factors of Osgood-Schlatter syndrome in a population-based sample of Brazilian adolescents. Am J Sports Med. 2011;39(2):415-420.

14. Krivickas LS, Feinberg JH. Lower extremity injuries in college athletes: relation between ligamentous laxity and lower extremity muscle tightness. Arch Phys Med Rehabil. 1996;77(11):1139-1143.

15. Carter C, Wilkinson J. Persistent joint laxity and congenital dislocation of the hip. J Bone Joint Surg Br. 1964;46:40-45.

16. Grahame R, Jenkins JM. Joint hypermobility-asset or liability? A study of joint mobility in ballet dancers. Ann Rheum Dis. 1972;31(2):109-111.

17. Fairbank JC, Pynsent PB, Philips H. Quantitative measurements of joint mobility in adolescents. Ann Rheum Dis. 1984;43(2):288-294.

18. Boyle KL, Witt P, Riegger-Krugh C. Intrarater and Interrater Reliability of the Beighton and Horan Joint Mobility Index. J Athl Train. 2003;38(4):281-285.

19. Bin Abd Razak HR, Bin Ali N, Howe TS. Generalized ligamentous laxity may be a predisposing factor for musculoskeletal injuries. $J \mathrm{Sci}$ Med Sport. 2013;pii:S1440-2440(13)00485-4.

20. Joźwiak M, Pietrzak S, Tobjasz F. The epidemiology and clinical manifestations of hamstring muscle and plantar foot flexor shortening. Dev Med Child Neurol. 1997;39:481-483.

21. Feldman DE, Shrier I, Rossignol M, Abenhaim L. Risk factors for the development of low back pain in adolescence. Am J Epidemiol. 2001;154(1):30-36.

22. Mierau D, Cassidy JD, Young-Hing K. Low-back pain and straight leg raising in children and adolescents. Spine (Phila Pa 1976). 1989;14(5):526-528.

23. Takata $\mathrm{K}$, Takahashi $\mathrm{K}$. Hamstring tightness and sciatica in young patients with disc herniation. J Bone Joint Surg Br. 1994;76(2):220-224.

24. Witvrouw E, Danneels L, Asselman P, D'Have T, Cambier D. Muscle flexibility as a risk factor for developing muscle injuries in male professional soccer players. A prospective study. Am J Sports Med. 2003;31(1):41-46.

25. Krivickas LS, Feinberg JH. Lower extremity injuries in college athletes: relation between ligamentous laxity and lower extremity muscle tightness. Arch Phys Med Rehabil. 1996;77(11):1139-1143.

26. Lipetz J, Kruse RJ. Injuries and special concerns of female figure skaters. Clin Sports Med. 2000;19(2):369-380.

27. Wilson EK, Lahurd AP, Wilckens JH. An unusual mechanism for injury of the anterior cruciate ligament in figure skating. Clin J Sport Med. 2012;22(2):160-162.

28. Offierski CM, MacNab I. Hip-spine syndrome. Spine. 1983;8(3): 316-321.

29. Osterås H, Garnæs KK, Augestad LB. Prevalence of musculoskeletal disorders among Norwegian female biathlon athletes. Open Access J Sports Med. 2013;4:71-78.

\section{Dovepress}

Visit http://www.dovepress.com/testimonials.php to read real quotes from published authors. 